\title{
HUBUNGAN BRAND IMAGE DAN KUALITAS PRODUK TERHADAP KEPUTUSAN PEMBELIAN ONLINE SHOP
}

\author{
BRAND RELATIONS IMAGE AND PRODUCT QUALITY \\ TOWARDS DECISIONS ON PURCHASE ONLINE SHOP
}

\author{
Rostini $^{1}$, Syahribulan ${ }^{2}$, Marin Toding $\mathrm{K}^{3}$ \\ Manajemen, Universitas Indonesia Timur \\ ${ }^{1}$ (rostinihasanuddin@gmail.com) ${ }^{2}$ (syahribulansyam07@gmail.com), \\ (rintoding@gmail.com)
}

\begin{abstract}
ABSTRAK
Penelitian ini bertujuan untuk mengetahui hubungan brand image dan kualitas produk terhadap keputusan pembelian online shop. Metode analisis data yang digunakan adalah analisis kuantitatif dan regresi linier berganda dengan bantuan aplikasi SPSS 22,0 for windows. Sampel dalam penelitian ini adalah 50 responden yang pernah melakukan pembelian online shop. Metode pengambilan sampel yang digunakan adalah metode purposive sampling. Hasil penelitian menunjukkan bahwa secara parsial (uji t) brand image dan kualitas produk tidak berhubungan terhadap keputusan pembelian online shop. Dengan koefesien determinasi $R$ Square $\left(\mathrm{R}^{2}\right)$ sebesar 1,5\% yang berarti variablel keputusan dipengaruhi oleh kedua variabel independen yaitu brand image dan kualitas produk. Sedangkan sisanya sebesar $98,5 \%$ dipengaruhi oleh variabel-variabel yang tidak diteliti dalam penelitian ini.
\end{abstract}

Kata Kunci: Brand image, kualitas produk dan keputusan pembelian

\section{ABSTRACT}

This study aims to determine the relationship of brand image and product quality on online shop purchasing decisions. The data analysis method used is quantitative analysis and multiple linear regression with the help of the SPSS 22.0 for windows application. The sample in this study were 50 respondents who had made an online shop purchase. The sampling method used was purposive sampling method. The results showed that partially ( $t$ test) brand image and product quality were not related to online shop purchasing decisions. With the coefficient of determination $R$ Square (R2) of $1.5 \%$ which means the decision variable is influenced by two independent variables namely brand image and product quality. While the remaining $98.5 \%$ is influenced by variables not examined in this study.

Keywords: Brand image, product quality and purchasing decision

\section{PENDAHULUAN}

Dampak dari majunya dunia usaha suatu negara membuat pasar menjadi semakin luas dan peluang ada dimanamana, namun sebaliknya persaingan menjadi semakin ketat dan sulit diprediksi. Kondisi ini menuntut perusahaan untuk menciptakan keunggulan kompetitif bisnisnya agar mampu bersaing secara berkesinambungan.Perusahaan yang ingin berkembang dan mendapatkan keunggulan kompetitif harus dapat memberikan produk berupa barang atau jasa yang berkualitas dan pelayanan yang baik kepada para pelanggan agar pelanggan merasa puas.

Adanya penggunaan internet yang semakin popular pada generasi masa kini.Kebanyakan orang saat ini sangat dekat dengan akses informasi dan dunia internet. Kondisi lingkungan yang mendukung untuk mengakses bentuk inovasi atau perubahan yang ada di lingkungan sekitar akibat adanya internet. 
Internet memberikan beragam fasilitas yang sangat memudahkan penggunanya untuk mengakses beragam informasi yang diinginkan sehingga para pengguna internet dimanjakan oleh beragam fasilitas tersebut.Beragam fasilitas yang disajikan oleh internet memberikan warna baru dalam segi belanja.

Online shop adalah salah satu yang disajikan internet yang memberikan berbagai kemudahan. Kemudahan yang disajikan dalam berbelanja yaitu efisiensi waktu, tanpa harus bertatap muka pelanggan bisa membeli barang yang diinginkan. Keunggulan pembelian secara online ini prosesnya dapat dengan mudah dilakukan cukup dengan membuka web atau social media online shop dengan jaringan internet. Hal inilah yang menjadi salah satu cara memuaskan kebutuhan konsumen di era persaingan yang begitu canggih seperti saat ini.

Berbagai teori perilaku konsumen dan pemasaran menyatakan bahwa kebutuhan manusia tidak saja dipengaruhi oleh motivasinya, melainkan juga hal-hal eksteral seperti budaya, social dan ekonomi.Fenomena persaingan ada yang iniakan semakin mengarahkan sistem Perekonomian Indonesia ke mekanisme pasar yang memposisikan pemasar untuk selalu mengembangkan dan merebut marketshare (pangsa pasar).Salah satun aset untuk mencapai keadaa tersebut adalah brand image (citra merek).

Dengan adanya merek, konsumen dapat membedakan suatu produk yang sejenis, sehingga dapat dilihat bagaimana merek dapat mempengaruhi penilaian konsumen dan citra merek (Brand Image) dari produk tersebut.Merek pada awalnya hanyalah pembeda dari suatu produk dengan produk lapinnya, namun kini telah mengalami perkembangan yang berpengaruh pada citra dari sebuah perusahaan. Citra Perusahaan (Organizational Image) selanjutnya memberikan pengaruh pada "Brand Image" dari perusahaan, dan produknya berpengaruh pula pada keputusan konsumen dalam melakukan pembelian pada merek produk tersebut.

Adapun yang menjadi tujuan penelitian ini adalah untuk mengetahui hubungan brand image dan kualitas produk pada keputusan pembelian online shop (studi kasus pada pengguna sosial media jejaring facebook).

\section{METODE}

Pendekatan penelitian yang digunakan dalam penelitian ini adalah metode penelitian deskriptif kuantitatif. Adapun objek penelitian ini adalah pada penggunan sosial media jejaring facebook. Variabel yang terlibat dalam penelitian ini adalah brand image sebagai variable bebas pertama (X1), kualitas produk sebagai variable bebas kedua (X2) dan keputusan pembelian sebagai variabel terikat (Y).

Populasi dari penelitian ini adalah pengguna sosial media jejaring facebook sebanyak 50 orang. Adapun teknik pengambilan sampel untuk menentukan sampel yang akan digunakan dalam penelitian ini menggunakan teknik total sampling, yaitu teknik pengambilan sampel di mana sampel sama dengan jumlah populasi pada tempat penelitian.

Teknik pengumpulan data yang digunakan dalam penelitian ini adalah dengan menggunakan angket atau kuesioner. Metode analisis yang digunakan dalam penelitian ini adalah dengan menggunakan analisis regresi linier berganda sebagai analisis preferensi yang digunakan untuk mengetahui efek brand image dan kualitas produk terhadap pengambilan keputusan pembelian online shop. Rumus yang digunakan adalah: Sumarsono (2009).

$\mathrm{Y}=\mathrm{a}+\mathrm{b} 1 \mathrm{X} 1+\mathrm{b} 2 \mathrm{X} 2+\mathrm{e}$

Dimana :

$\mathrm{Y} \quad=$ Keputusan pembelian

$\mathrm{X} 1=$ Brand Image ( Citra Merek)

$\mathrm{X} 2=$ Kualitas Produk

b1 - b2= Koefisien Regresi

a $\quad=$ Konstanta

e $\quad=$ Standar Error 
Pengujian hipotesis menggunakan uji $\mathrm{t}$ $<0,05=$ signifikan dan $>0,05=$ tidak signifikan

\section{HASIL DAN PEMBAHASAN}

Responden dalam penelitian ini beragam, baik itu perempuan maupun lakilaki, usia yang berbeda, tingkat pendidikan dan pekerjaan. Penelitian ini dilakukan dengan menyebarkan kuesioner online dan kuesioner langsung di kampus Universitas Indonesia Timur. Pada penelitian ini kuesioner online digunakan dengan menggunakan google drive dan disebarkan melalui sosial media facebook. Setelah dibuat format kuesioner beserta pernyataannya maka peneliti menyebarkan kuesioner tersebut kepada rekan-rekan peneliti di facebook dan juga di kampus UIT Makassar. Saat menyebarkan peneliti memberikan link yang apabila diklik akan menuju kuesioner online sudah disediakan sehingga responden bisa menjawabnya dan juga peneliti menyebarkan kuesioner yang sudah diprintout di kampus sehingga responden bisa langsung mengisi kuesioner tersebut.

Karakteristik responden yang diamati dalam penelitian ini adalah jenis kelamin, umur dan profesi dengan jumlah sebanyak 6 orang atau $12 \%$ dan perempuan sebanyak 44 orang atau $88 \%$. Deskripsi karakteristik responden disajikan pada tabel 1 sebagai berikut :

Tabel 1. Tabel Karakteristik Responden Berdasarkan Jenis Kelamin

\begin{tabular}{lcc}
\hline \multicolumn{1}{c}{ Jenis Kelamin } & Frekuensi ( F) & Persentase (\%) \\
\hline Laki-laki & 6 & 12 \\
\hline Perempuan & 44 & 88 \\
\hline Total & 50 & 100 \\
\hline
\end{tabular}

Tabel 2. Karakteristik Responden Berdasarkan Umur

\begin{tabular}{lcc}
\hline \multicolumn{1}{c}{ Umur } & Frekuensi $\mathbf{( F )}$ & Persentase ( \%) \\
\hline $16-20$ Tahun & 9 & 18 \\
\hline $21-25$ Tahun & 32 & 64 \\
\hline $26-30$ Tahun & 7 & 14 \\
\hline $31-35$ Tahun & 1 & 2 \\
\hline$>35$ Tahun & 1 & 2 \\
\hline Jumlah & 50 & 100 \\
\hline
\end{tabular}

Tabel 3. Karakteristik Responden Berdasarkan Status Pekerjaan

\begin{tabular}{lcc}
\hline \multicolumn{1}{c}{ Status Pekerjaan } & Frekuensi ( F) & Persentase (\%) \\
\hline Mahasiswa & 34 & 48 \\
\hline PNS & 2 & 4 \\
\hline Wirausaha & 2 & 4 \\
\hline Wiraswasta & 12 & 24 \\
\hline Jumlah & 50 & 100 \\
\hline
\end{tabular}

Berdasarkan tabel 2, terlihat sebanyak 9 orng atau $28 \%$ yang berumur dibawah 16-20 tahun, 32 orang atau $64 \%$ yang berumur 21-25 tahun tahun, 26-30 tahun 7 orang atau 14\%, 31-35 tahun 1 orang atau $2 \%$ dan diatas 35 tahun 1 orang atau $2 \%$. Adapun profesi dalam penelitian ini terdiri atas mahasiswa, PNS, wirausaha dan wiraswasta. Berdasarkan tabel 3, terlihat sebanyak 34 orang atau $68 \%$ adalah mahasiswa/i , 2 orang atau $4 \%$ sebagai PNS, 2 orang atau $4 \%$ sebagai wirausaha dan 12 orang atau $24 \%$ sebagai wiraswasta Ini menunjukkan bahwa 
kebanyakan kalangan mahasiswa yang paling berminat berbelanja online. Penelitian ini menggunakan skala likert dengan bobot tertinggi di tiap pernyataan adalah 5 dan bobot terendah adalah 1 . Dengan jumlah responden sebanyak 50 orang, maka:

$$
\text { range }=\frac{\text { skor tertinggi }- \text { skor terendah }}{\text { range skor }}
$$

Skor tertinggi $: 50 \times 5=250$

Skor terendah : $50 \times 1=50$

Sehingga range untuk hasil penelitian, yaitu : $\frac{250-50}{5}=40$

Range skor :

$$
\begin{array}{ll}
50-90 & =\text { sangat rendah } \\
91-131 & =\text { rendah } \\
132-172 & =\text { cukup }
\end{array}
$$

$$
\begin{array}{ll}
173-213 & =\text { tinggi } \\
214-253 & =\text { sangat tinggi }
\end{array}
$$

Deskripsi penelitian adalah tanggapan responden mengenai hubungan brand image dan kualitas produk terhadap keputusan pembelian online shop. Variabel bebas (X1 dan X2) yang terdiri atas brand image dan kualitas produk terhadap keputusan pembelian sebagai variabel terikat (Y) dijelaskan sebagai berikut:

\section{Brand Image (Citra Merek)}

Untuk melihat tanggapan responden

\begin{tabular}{|c|c|c|c|c|c|c|c|c|c|c|c|c|}
\hline \multirow{3}{*}{ No } & \multirow{3}{*}{ Pernyataan } & \multicolumn{10}{|c|}{ Jawaban Responden } & \multirow{3}{*}{ Skor } \\
\hline & & \multicolumn{2}{|c|}{ STS } & \multicolumn{2}{|c|}{ TS } & \multicolumn{2}{|c|}{$\mathrm{KS}$} & \multicolumn{2}{|c|}{$\mathrm{S}$} & \multicolumn{2}{|c|}{$\mathrm{SS}$} & \\
\hline & & $\Sigma$ & $\%$ & $\Sigma$ & $\%$ & $\Sigma$ & $\%$ & $\Sigma$ & $\%$ & $\Sigma$ & $\%$ & \\
\hline 1 & $\mathrm{X} 1.1$ & 0 & 0 & 0 & 0 & 4 & 8 & 29 & 58 & 17 & 34 & 213 \\
\hline 2 & $\mathrm{X} 1.2$ & 0 & 0 & 0 & 0 & 3 & 6 & 33 & 66 & 14 & 28 & 211 \\
\hline 3 & $\mathrm{X} 1.3$ & 0 & 0 & 0 & 0 & 4 & 8 & 30 & 60 & 16 & 32 & 212 \\
\hline 4 & $\mathrm{X} 1.4$ & 0 & 0 & 0 & 0 & 2 & 4 & 31 & 62 & 17 & 34 & 215 \\
\hline 5 & $\mathrm{X} 1.5$ & 0 & 0 & 0 & 0 & 5 & 10 & 30 & 60 & 15 & 30 & 210 \\
\hline 6 & X1.6 & 0 & 0 & 0 & 0 & 5 & 10 & 21 & 42 & 24 & 48 & 219 \\
\hline 7 & X1.7 & 0 & 0 & 2 & 4 & 6 & 12 & 22 & 44 & 20 & 40 & 210 \\
\hline 8 & $\mathrm{X} 1.8$ & 0 & 0 & 0 & 0 & 2 & 40 & 30 & 60 & 18 & 36 & 216 \\
\hline 9 & X1.9 & 0 & 0 & 0 & 0 & 2 & 4 & 34 & 68 & 14 & 28 & 212 \\
\hline & & & & & ata & & & & & & & 213 \\
\hline
\end{tabular}
terhadap indikator-indikator dan juga perhitungan skor untuk variabel citra merek (brand image) dapat dilihat pada tabel 4 .

Tabel 4. Tanggapan responden mengenai brand image di online shop

Dari hasil tersebut dapat disimpulkan bahwa tanggapan responden terhadap variabel brand image (citra merek) berada pada range ke empat, yaitu tinggi, dengan nila rata-rata 213 . Hal ini berarti responden setuju dengan pertanyaan-pertanyaan yang tertuang dalam kuesioner berkaitan dengan variabel brand image.

\section{Kualitas Produk}

Dari hasil penelitian yang digambarkan pada tabel 5, dapat disimpulkan bahwa tanggapan responden terhadap variabel kualitas produk berada pada range ke empat, yaitu tinggi dengan rata-rata nilai 208. Hal ini berarti responden setuju dengan pertanyaanpertanyaan yang tertuang dalam kuesioner berkaitan dengan variabel kualitas produk. 
Tabel 5. Tanggapan Responden Mengenai Kualitas Produk Online

\begin{tabular}{|c|c|c|c|c|c|c|c|c|c|c|c|c|}
\hline \multirow{3}{*}{ No } & \multirow{3}{*}{ Pernyataan } & \multicolumn{10}{|c|}{ Jawaban Responden } & \multirow{3}{*}{ Skor } \\
\hline & & \multicolumn{2}{|c|}{ STS } & \multicolumn{2}{|c|}{$\mathrm{TS}$} & \multicolumn{2}{|c|}{$\mathrm{KS}$} & \multicolumn{2}{|c|}{$S$} & \multicolumn{2}{|c|}{ SS } & \\
\hline & & $\Sigma$ & $\%$ & $\Sigma$ & $\%$ & $\Sigma$ & $\%$ & $\Sigma$ & $\%$ & $\Sigma$ & $\%$ & \\
\hline 1 & $\mathrm{X} 2.1$ & 0 & 0 & 0 & 0 & 4 & 8 & 28 & 56 & 18 & 36 & 214 \\
\hline 2 & $\mathrm{X} 2.2$ & 0 & 0 & 0 & 0 & 5 & 10 & 21 & 42 & 24 & 48 & 219 \\
\hline 3 & $\mathrm{X} 2.3$ & 0 & 0 & 1 & 2 & 13 & 26 & 18 & 36 & 18 & 36 & 203 \\
\hline 4 & $\mathrm{X} 2.4$ & 0 & 0 & 1 & 2 & 16 & 32 & 16 & 32 & 17 & 34 & 199 \\
\hline 5 & $X 2.5$ & 0 & 0 & 0 & 0 & 16 & 32 & 20 & 40 & 14 & 28 & 198 \\
\hline 6 & X2.6 & 0 & 0 & 0 & 0 & 9 & 18 & 15 & 30 & 26 & 52 & 217 \\
\hline \multicolumn{12}{|c|}{ Rata-rata } & 208 \\
\hline
\end{tabular}

\section{Keputusan Pembelian}

Untuk melihat tanggapan responden terhadap indikator-indikator dan juga perhitungan skor untuk variabel keputusan pembelian dapat dilihat pada Tabel 6. Dari hasil tersebut dapat disimpulkan bahwa tanggapan responden terhadap keputusan pembelian sangat tinggi. Hal ini berarti responden setuju dengan pertanyaanpertanyaan yang tertuang dalam kuesioner berkaitan dengan variabel keputusan pembelian.

Tabel 6. Tanggapan Responden Mengenai Keputusan Pembelian

\begin{tabular}{|c|c|c|c|c|c|c|}
\hline \multirow{3}{*}{ No } & \multirow{3}{*}{ Pernyataan } & \multicolumn{4}{|c|}{ Jawaban Responden } & \multirow{3}{*}{ Skor } \\
\hline & & \multicolumn{2}{|c|}{ TIDAK } & \multicolumn{2}{|c|}{ YA } & \\
\hline & & $\Sigma$ & $\%$ & $\Sigma$ & $\%$ & \\
\hline 1 & Y & 3 & 6 & 47 & 94 & 47 \\
\hline \multicolumn{6}{|c|}{ Rata-rata } & 47 \\
\hline
\end{tabular}

Hasil pengujian hipotesis pertama yang menyatakan bahwa "Brand Image Berhubungan Dengan Keputusan Pembelian Online Shop". Berdasarkan hasil penelitian ditemukan bahwa variabel brand image tidak berhubungan. Hal ini didukung oleh hasil uji t yaitu nilai $t_{\text {hitung }}<$ $\mathrm{t}_{\text {tabel }}$ yaitu $0.643<2.011$. sehingga dalam penelitian ini brand image tidak berhubungan terhadap keputusan pembelian online shop dikarenakan kebanyakan orang dalam melakukan pembelian online shop lebih mengutamakan harga dibandingkan brand. Hasil pengujian hipotesis kedua yang menyatakan bahwa "Kualitas Berhubungan dengan Keputusan Pembelian Online Shop". Berdasarkan dari hasil penelitian ditemukan bahwa variabel kualitas produk tidak berhubungan. Hal ini didukung oleh hasil uji $\mathrm{t}$ yaitu $\mathrm{t}_{\text {hitung }}<\mathrm{t}_{\text {tabel }}$ yaitu $0.260<2.011$. sehingga dalam penelitian ini kualitas produk tidak berhubungan terhadap keputusan pembelian online shop dikarenakan kebanyakan orang lebih memperhatikan gambar ketika ingin melakukan pembelian online shop dibandingkan dengan kualitas produk.

Penelitian ini bertolak belakang dengan penelitian terdahulu yang dilakukan oleh Wayan Adi Virawan (2013) tentang "Pengaruh Kualitas Produk dan Citra Merek Terhadap Keputusan Pembelian Helm INK" (Studi Pada Mahasiswa Fakultas Ekonomi Universitas 
Negeri Yogyakarta Pengguna Helm Merek INK) yang mempunyai hasil bahwa terdapat pengaruh yang signifikan antara variabel harga, kualitas produk, terhadap keputusan pembelian helm merk INK. Namun hasil penelitian ini mendukung teori yang dikemukakan oleh Kotler (2010) bahwa keputusan pembelian adalah tindakan dari konsumen mau membeli atau tidak terhadap suatu produk. Online shop adalah satu cara pembelian yang menggunakan internet dalam proses jual belinya. Banyak orang mengambil keputusan berbelanja di online shop tidak memperhatikan brand image (citra merek) dan kualitas produk karena kebanyakan orang lebih tergiur dengan harga yang murah, gambar iklan yang menarik serta produk-produk yang diperjual belikan di online shop misalnya pakaian selalu memberikan penawaran dengan modelmodel terbaru.

\section{KESIMPULAN DAN SARAN}

Berdasarkan hasil penelitian maka dapat ditarik beberapa kesimpulan bahwa bahwa secara parsial (uji t) brand image dan kualitas produk tidak berhubungan terhadap keputusan pembelian online shop. Dengan koefesien determinasi $R$ Square $\left(\mathrm{R}^{2}\right)$ sebesar $1,5 \%$ yang berarti variablel keputusan dipengaruhi oleh kedua variabel independen yaitu brand image dan kualitas produk. Sedangkan sisanya sebesar 98,5\% dipengaruhi oleh variabel-variabel yang tidak diteliti dalam penelitian ini.

Adapun saran yang peneliti ajukan yaitu bahwa hendaknya penelitian ini menjadi bahan evaluasi bagi owner online shop dalam meningkatkan keputusan pembelian dengan memperbaiki brand image (citra merek) dari produk yang ditawarkan. Dari segi kualitas produk agar owner online shop meningkatkan kualitas produk yang ditawarkan kepada pembeli agar pembeli tidak merasa kecewa ketika produk yang diterima berbeda dengan iklan.

\section{UCAPAN TERIMA KASIH}

Ucapan terima kasih peneliti sampaikan kepada segenap pengguna sosial media jejaring facebook sebanyak 50 orang yang telah menjadi sampel penelitian, serta ucapan terima kasih pula kepada civitas akademika Universitas Indonesia Timur (UIT) yang memiliki peran dalam terlaksananya penelitian ini dan pihak-pihak yang telah memberikan bantuan sarana maupun prasarana yang peneliti butuhkan.

\section{DAFTAR PUSTAKA}

Arifin, Zainal. 2008. Metodelogi Penelitian Pendidikan. Surabaya: Lentera Cendikia.

Durianto, Darmadi. 2011. Strategi Menaklukkan Pasar Melalui Riset Ekuitas dan Perilaku Merek. Jakarta: PT Gramedia Pustaka Utama.

Ferrinadewi, Erna. 2008. Merek dan Psikologi Konsumen. Yogyakarta : Graha Ilmu

Freddy, Rangkuti. 2009. Strategi Promosi Yang Kreatif. Jakarta: Gramedia Pustaka Utama.

Ginting, Nembah. 2011. Manajemen Pemasaran. Bandung: Yrama Widya.

Hasibuan, Malayu S.P. 2008. Manajemen Sumber Daya Manusia. Jakarta: PT Bumi Aksara.

Kartajaya, Hermawan. 2010. Brand Operation The Offical MIM Academy. Jakarta: Erlangga.

Kotler, Philip dan Amstrong, Garry. 2008. Prinsip-prinsip Pemasaran Edisi Ke-12 Jilid 1. Jakarta: Erlangga 
Kotler, Philip dan Amstrong, Garry. 2012. Prinsip-prinsip Pemasaran Edisi Ke-13 Jilid 1. Jakarta: Erlangga

Kotler, Philip dan Keller Kevin Lanne . 2008. Manajemen Pemasaran Edisi $\mathrm{Ke}$-12. Jakarta: PT Indeks.

Kotler, Philip dan Keller Kevin Lanne. 2009. Manajemen Pemasaran Jilid 1 Edisi Ke-13.Jakarta: Erlangga.

Kotler, Philip. 2010. Manajemen Pemasaran Edisi Ke-13,Jilid 1. Jakarta: Erlangga.

Moleong, J. Lexy. 2009. Metode Penelitian Kualitatif. Bandung: PT Remaja Rosdakaya.

Schiffman dan Kanuk. 2007. Perilaku Konsumen Edisi Ke-2. Jakarta: PT Indeks.

Sugiyono. 2012. Metode Penelitian Bisnis. Bandung: Alfabeta.

Sumarsono, Sonny. 2009. Ekonomi Sumber Daya Manusia Teori dan Kebijakan Publik. Yogyakarta: Graha Ilmu.

Swastha, Basu dan Handoko, Hani. 2011. Manajemen Pemasaran Analisis Perilaku Konsumen. Yogyakarta: BPFE.

Tjiptono, Fandy. 2008. Strategi Pemasaran Edisi Ke-3. Yogyakarta: Andi offset. 